\title{
Inspiring Young Children to Engage in Computational Thinking In and Out of School (Research to Practice)
}

\section{Dr. Morgan M. Hynes, Purdue University, West Lafayette}

Dr. Morgan Hynes is an Assistant Professor in the School of Engineering Education at Purdue University and Director of the FACE Lab research group at Purdue. In his research, Hynes explores the use of engineering to integrate academic subjects in K-12 classrooms. Specific research interests include design metacognition among learners of all ages; the knowledge base for teaching K-12 STEM through engineering; the relationships among the attitudes, beliefs, motivation, cognitive skills, and engineering skills of K-16 engineering learners; and teaching engineering.

Dr. Monica E. Cardella, Purdue University, West Lafayette

Monica E. Cardella is the Director of the INSPIRE Research Institute for Pre-College Engineering and is an Associate Professor of Engineering Education at Purdue University.

\section{Prof. Tamara J. Moore, Purdue University, West Lafayette}

Tamara J. Moore, Ph.D., is a Professor in the School of Engineering Education and Director of STEM Integration in the INSPIRE Institute at Purdue University. Dr. Moore's research is centered on the use of engineering design-based STEM integration in K-12 and postsecondary classrooms in order to help students make connections among the STEM disciplines and achieve deep understanding. Her work focuses on defining STEM integration, including computational thinking, and investigating its power for student learning.

\section{Dr. Sean P. Brophy, Purdue University, West Lafayette}

Dr. Sean Brophy is the director of Student Learning for the INSPIRE Pre-college Research Institute at Purdue University. His research in engineering education and learning sciences involves developing young children's cognitive ability to think and reason during complex problem solving activities. As part of this research he explores new methods to enhance informal and formal learning experiences using technology.

\section{Dr. Senay Purzer, Purdue University, West Lafayette}

enay Purzer is an Associate Professor in the School of Engineering Education. She is the recipient of a 2012 NSF CAREER award, which examines how engineering students approach innovation. She serves on the editorial boards of Science Education and the Journal of Pre-College Engineering Education (JPEER). She received a B.S.E with distinction in Engineering in 2009 and a B.S. degree in Physics Education in 1999. Her M.A. and Ph.D. degrees are in Science Education from Arizona State University earned in 2002 and 2008, respectively.

\section{Kristina Maruyama Tank, Iowa State University}

Kristina M. Tank is an Assistant Professor of Science Education in the School of Education at Iowa State University. She currently teaches undergraduate courses in science education for elementary education majors. As a former elementary teacher, her research and teaching interests are centered around improving elementary students' science and engineering learning and increasing teachers' use of effective STEM instruction in the elementary grades. With the increased emphasis on improved teaching and learning of STEM disciplines in K-12 classrooms, Tank examines how to better support and prepare pre-service and in-service teachers to meet the challenge of integrating STEM disciplines in a manner that supports teaching and learning across multiple disciplines. More recently, her research has focused on using literacy to support scientific inquiry, engineering design, and STEM integration.

Dr. Muhsin Menekse, Purdue University, West Lafayette 
Muhsin Menekse is an assistant professor at Purdue University with a joint appointment in the School of Engineering Education and the Department of Curriculum \& Instruction. Dr. Menekse's primary research focus is on students' learning of complex tasks and concepts in STEM domains. Specifically, he investigates how classroom activities and learning environments affect engagement and learning in engineering and science domains. His second research focus in on exploring verbal interactions in small groups and student teams. And his third research focus is on metacognition and its implications for learning. Much of this research focuses on learning processes in classroom settings. Dr. Menekse is the recipient of the 2014 William Elgin Wickenden Award by the American Society for Engineering Education. His research has been generously funded by grants from the Institute of Education Sciences (IES), Purdue Research Foundation (PRF), and National Science Foundation (NSF).

\section{Dr. Ibrahim H. Yeter, Purdue University, West Lafayette}

Ibrahim H. Yeter is a Postdoctoral Researcher in his second year in the INSPIRE-Research Institute for Pre-College Engineering in the School of Engineering Education at Purdue University. He completed his $\mathrm{PhD}$ degree majoring in Curriculum and Instruction with an emphasis in Engineering Education and minoring in Educational Psychology as well as an MS degree in Petroleum Engineering at Texas Tech University. He also obtained an MEd degree from Clemson University. His research interests focus on teacher education and students learning issues within Engineering Education/Pedagogy and Computational Thinking/Pedagogy field of studies. He received national and international recognitions including an Early Career Researcher award from European Science Education Research Association (ESERA) and a Jhumki Basu Scholar award from National Association for Research in Science Teaching (NARST). In addition, he is one of two scholarship recipients awarded by NARST to attend the ESERA summer research program in České Budějovice, Czech Republic in 2016. He can be reached at iyeter@ purdue.edu.

\section{Ms. Hoda Ehsan, Purdue University, West Lafayette}

Hoda is a Ph.D. student in the School of Engineering Education, Purdue. She received her B.S. in mechanical engineering in Iran, and obtained her M.S. in Childhood Education and New York teaching certification from City College of New York (CUNY-CCNY). She is now a graduate research assistant on $\mathrm{STEM}+\mathrm{C}$ project. Her research interests include designing informal setting for engineering learning, and promoting engineering thinking in differently abled students in informal and formal settings. 


\title{
Inspiring Young Children to Engage in Computational Thinking In and Out of School (Research to Practice)
}

\begin{abstract}
Integrating science, technology, engineering, and mathematics (STEM) subjects in pre-college settings is seen as critical in providing opportunities for children to develop knowledge, skills, and interests in these subjects and the associated critical thinking skills. More recently computational thinking (CT) has been called out as an equally important topic to emphasize among pre-college students. The authors of this paper began an integrated STEM+CT project three years ago to explore integrating these subjects and literacy in a curriculum for 5-8-year-old students. We reported on the development of this project and an analysis of how the existing curriculum highlighted CT knowledge and skills, and how we expected the curriculum to engage students in CT in an ASEE conference paper in 2016. This paper reports on the evolution of the project and curriculum. Part of this evolution included the defining of CT and its associated competencies and what it would look like for this young age group. In this paper, we discuss this evolution as well as how we have operationalized the competencies with data from classroom testing. At the outset of this project, there were few resources that specifically considered teaching CT with 5-8-year-old children and fewer clear examples of what it looked like for children to engage in CT. However, there were many, sometimes competing, definitions and approaches to CT more generally. After further review of the literature and classroom testing of our revised curriculum, the team developed definitions for the following CT competencies: abstraction; algorithms and procedures; automation; data collection; data analysis; data representation; debugging/troubleshooting; problem decomposition; parallelization; simulation; and pattern recognition. Analysis of hundreds of students and tens of teachers implementing the curriculum allowed us to develop concrete examples of how students engage in CT competencies as well as how kindergarten through second grade teachers foster CT competency development. We report on these examples and how they informed the development of the integrated STEM+CT curriculum.
\end{abstract}

\section{Introduction}

Integrating science, technology, engineering, and mathematics (STEM) subjects in pre-college settings is seen as critical in providing opportunities for children to develop knowledge, skills, and interests in these subjects and the associated critical thinking skills (Moore, et al., 2014). More recently computational thinking (CT) has been called out as an equally important topic to emphasize among pre-college students. The authors of this paper began an integrated STEM+CT project three years ago to explore integrating these subjects through a science center exhibit and a curriculum for 5-8-year-old students. We reported on the development of this project and an analysis of how the existing curriculum highlighted CT knowledge and skills, and how we expected the curriculum to engage students in CT in an ASEE conference paper in 2016 (Hynes et al., 2016). This paper reports on the evolution of the project, development of the science center exhibit, and revision of the curriculum after working with 60 teachers in 15 schools and a local science center to engage young children in these activities. Part of this evolution included the refining of a set of CT competencies and what it would look like for this young age group. In this 
paper, we discuss this evolution as well as how we have operationalized the CT competencies with data from science center and classroom testing.

At the outset of this project, there were few resources that specifically considered teaching CT with 5-8-year-old children and fewer clear examples of what it looked like for children to engage in CT. However, there were many, sometimes competing, definitions and approaches to CT more generally. After further review of the literature and some laboratory and classroom testing with children, the team refined definitions for the following CT competencies: abstraction; algorithms and procedures; automation; data collection; data analysis; data representation; debugging/troubleshooting; problem decomposition; parallelization; simulation; and pattern recognition. Analysis of hundreds of students and tens of teachers implementing the curriculum allowed us to develop concrete examples of how students engaged in CT competencies as well as how kindergarten through second grade teachers fostered CT competency development. We report on these examples and how they informed the development of the integrated STEM+CT science center exhibit and curriculum.

\section{Evolution of CT competencies for K-2 students}

Developing computational thinking (CT) has recently emerged as an important educational objective in a world that is advancing technologically computational devices and systems are collecting and analyzing data to shape the world around us. This recent push has resulted in numerous groups proposing vocabulary and definitions for what comprises CT. As we first embarked on this project, we adopted the CT Vocabulary and Progression Chart provided by the CSTA \& ISTE (2011) as we reported in a 2016 ASEE paper (Hynes et al, 2016). However, as we progressed in the project, we conducted a more thorough review of CT competencies from other works (Barr \& Stephenson, 2011; Brennan \& Resnick, 2012; Cserkawskit \& Lyman, 2015; Grover \& Pea, 2013, Lye \& Koh, 2014; Wing, 2016). Through this review we refined some the definitions, added new ones from our initial 2016 list, and then translated them into language appropriate for K-2 teachers. Table 1 shows the original CT competencies along with two additions we have since added--debugging/troubleshooting and pattern recognition. With this list of eleven competencies, we do not imply that a lesson or unit for K-2 students should address them all. Instead, these are the types of competencies we wanted to look to incorporate, highlight, and then observe students enacting.

From this list, we then set out to refine the PictureSTEM integrated STEM curriculum units to more explicitly address CT as well as develop science center activities that would engage young children and their parents in engineering and CT ideas. Most recent published studies from the project suggest that students in kindergarten, first and second grade levels are capable of practicing CT competencies through integrated STEM activities (Dandridge et al., 2019; Lowe, Brophy, \& Cardella, 2019). What follows are brief descriptions of how these two learning activities were developed from a subset of these CT competencies as well as examples of how students demonstrated their engagement in these competencies. We do not present the comprehensive work we completed, but instead a sampling of the work as a demonstration as to how this can look to keep this work brief. 
Table 1: Computational Thinking Competencies (* - indicates competency added after literature review)

\begin{tabular}{|c|l|}
\hline $\begin{array}{c}\text { CT } \\
\text { Competency }\end{array}$ & \multicolumn{1}{|c|}{ Definitions } \\
\hline Abstraction & Identifying and utilizing the structure of concepts/main ideas \\
\hline Algorithms and Procedures & $\begin{array}{l}\text { Following, identifying, using, and creating an ordered set of } \\
\text { instructions (i.e., through selection, iteration and recursion) }\end{array}$ \\
\hline Automation & $\begin{array}{l}\text { Assigning appropriate set of tasks to be done repetitively by } \\
\text { computers }\end{array}$ \\
\hline Data Collection & Gathering information pertinent to solve a problem \\
\hline Data Analysis & Making sense of data by identifying trends \\
\hline Data Representation & $\begin{array}{l}\text { Organizing and depicting data in appropriate ways to } \\
\text { demonstrate relationships among data points via } \\
\text { representations such as graphs, charts, words or images }\end{array}$ \\
\hline Simulations & $\begin{array}{l}\text { Developing a model or a representation to imitate natural and } \\
\text { artificial processes }\end{array}$ \\
\hline Pattern Recognition* & Observing patterns, trends and regularities in data \\
\hline Problem Decomposition & $\begin{array}{l}\text { Breaking down data, processes or problems into smaller and } \\
\text { more manageable components to solve a problem }\end{array}$ \\
\hline reach a goal
\end{tabular}

\section{CT Competencies as designed in PictureSTEM integrated STEM units}

The PictureSTEM integrated STEM units employ engineering-design based STEM integration as well as reading, with each unit containing 6 paired reading and STEM content lessons and one introductory lesson to introduce engineering design, their client, and the design problem. On the whole, the reading lesson provides students with content and background and uses the Common Core State Standards for Literacy to guide student learning with appropriate reading content. The STEM lessons focus on science, mathematics, computational thinking and/or engineering content and use the relevant standards (Common Core State Standards for Mathematics, Next Generation Science Standards, etc.) to align content, but each integrates the engineering design context into the content learning throughout the unit. 
Prior to the start of the grant, the units had only 5 paired lessons and no introductory lesson. Through the work on the STEM+C grant, the units were revised to explicitly call out computational thinking and focus a bit on problem scoping. For each unit, the introductory lesson and one set of paired reading and CT lessons were added to the curriculum. As an example, we will describe the computational thinking changes in the first-grade unit, Designing Hamster Habitats, in detail. The reading lesson added was based on the book, Joey and Jet by James Yang. This book highlights a boy and his dog playing fetch. It takes the reader through the game of fetch and allows the reader to travel with the dog through all of the obstacles to get the ball and then reverses those obstacles to get it back. It provides a classic sequencing of events for the readers, which is a reading learning objective. As it happens, sequencing is also a computational thinking learning objective as part of developing an algorithm, so we built a flowchart-based card game that allowed the students to try to sequence the events of the story onto the cards. See Figure 1. Note also that Joey and Jet used preposition words which students filled in on the cards as practice with these words.

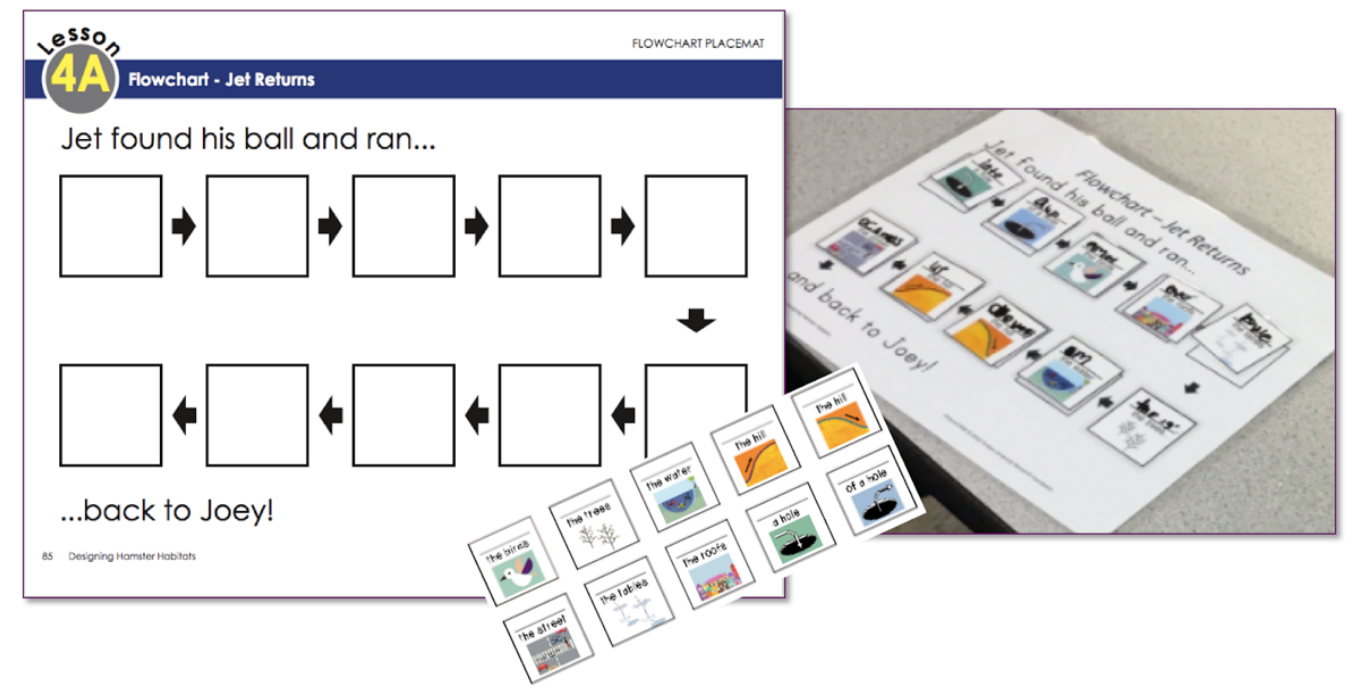

Figure 1. Joey and Jet flow chart mat to sequence how Jet returns the ball to Joey during their game of fetch from the story.

For the computational thinking STEM lesson, we had the students using tangrams to develop algorithms. The students had used tangrams in a previous set of lessons to learn about 2D shapes, so this lesson connects to that one - but focuses on the CT competency of algorithms. In this lesson, students follow algorithms, decide if predetermined algorithms will always produce equivalent results or not, developed their own algorithms, and determined if they produced an algorithm that will always provide equivalent results or not. Figure 2 provides an image of the activity. 


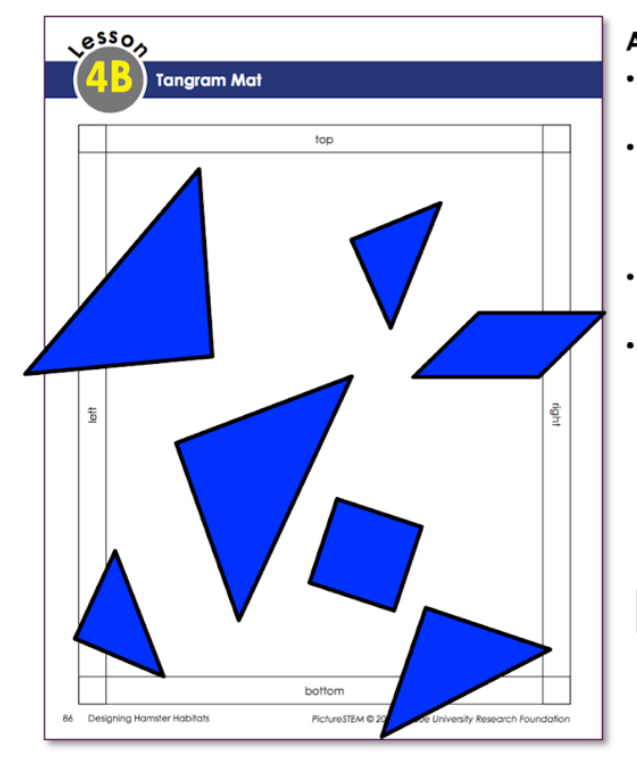

Algorithm 1:

- Use the two large triangles.

- Put the long edge of each triangle together to make a big square.

Use the medium triangle.

Put the long edge of the medium triangle against the top of the square.

Figure 2. Joey and Jet tangram mat to follow and develop algorithms.

Each of the other two units, likewise, added CT competencies. The kindergarten unit, Designing Paper Baskets, focused on the problem decomposition, pattern recognition, and debugging/troubleshooting CT competencies, and the second grade unit, Designing Toy Box Organizers, focused on Algorithms and Procedures and Simulations CT competencies.

The kindergarten unit was revised to more deliberately reinforce the pattern recognition CT competency by adding additional challenges where students shifted between representations of patterns by identifying them by color, by color and letter, and by letter. For example, the following student work displays evidence of the Pattern Recognition CT competency. The student was asked to first color the next box in the pattern (see figure 3 ). After completing coloring, the student was asked to complete the next following tasks which were writing the next letter and coloring the pattern (see figure 4). To scaffold the student's understanding of Pattern Recognition CT competency skill, an additional task was reinforced by using letters (see figure 5) to describe the colored patterns in the figure 3.
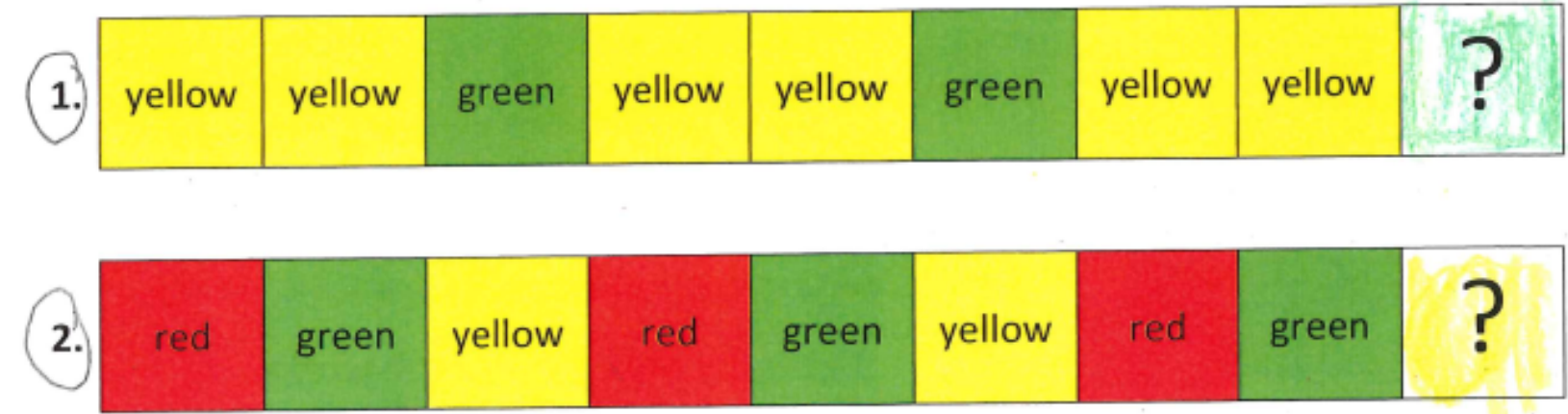

Figure 3. Colored patterns 


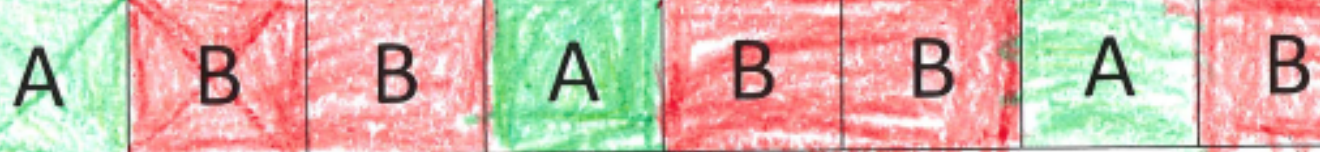

Figure 4. Coloring and placing pattern

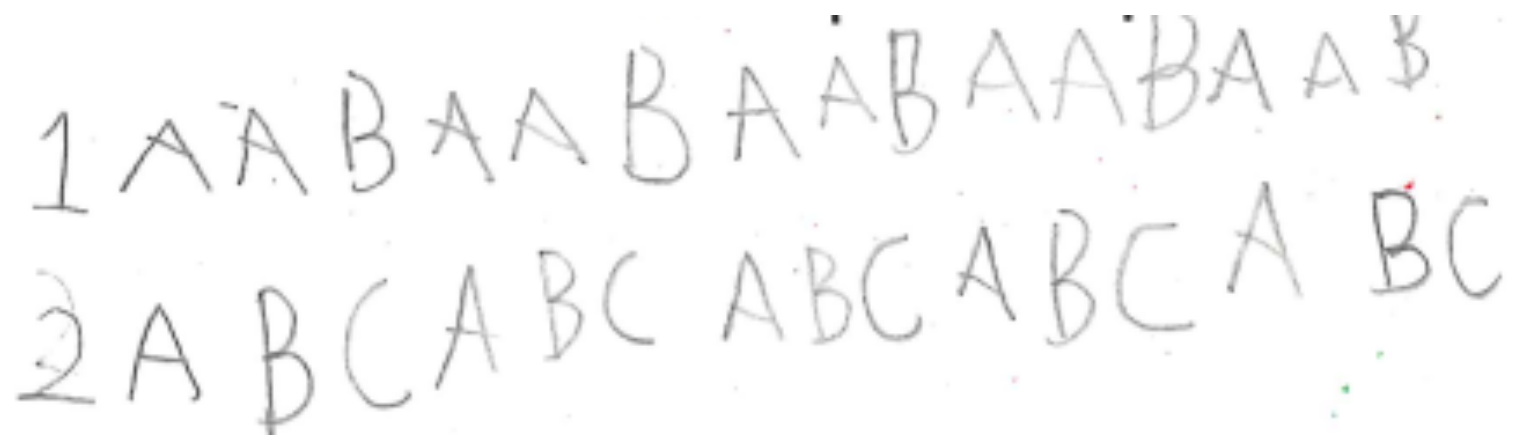

Figure 5. Using letters to describe the patterns

Furthermore, the data provided evidence that kindergarten students were able to continuously demonstrate their CT competencies in pattern recognition throughout the project implementation. For example, students were asked to complete the following tasks by using letters to show the pattern that they see in the boxes below in figure $6,7,8$, and 9 . Finally, they were asked to create their own pattern by coloring and/or providing letter patterning as seen in figure 10,11 , and 12 .

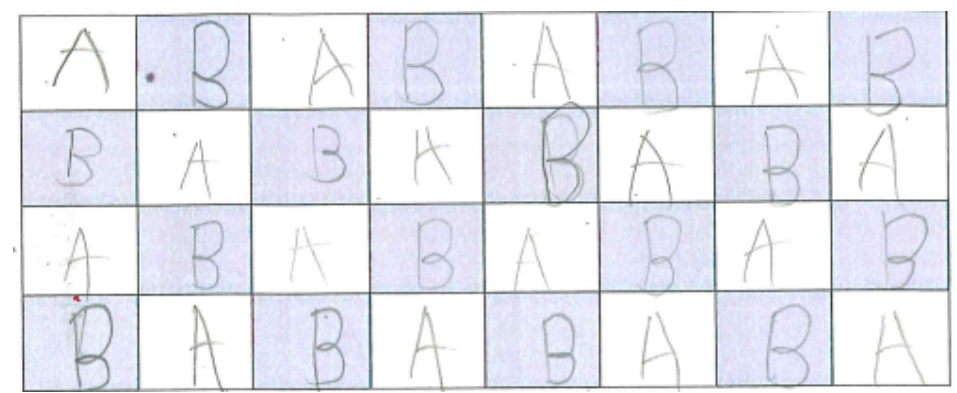

Figure 6. Using letters to show the pattern

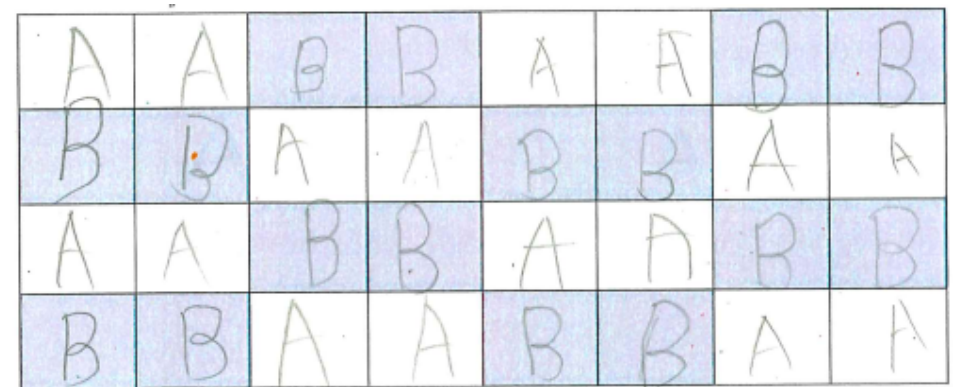

Figure 7. Using letters to show the pattern 


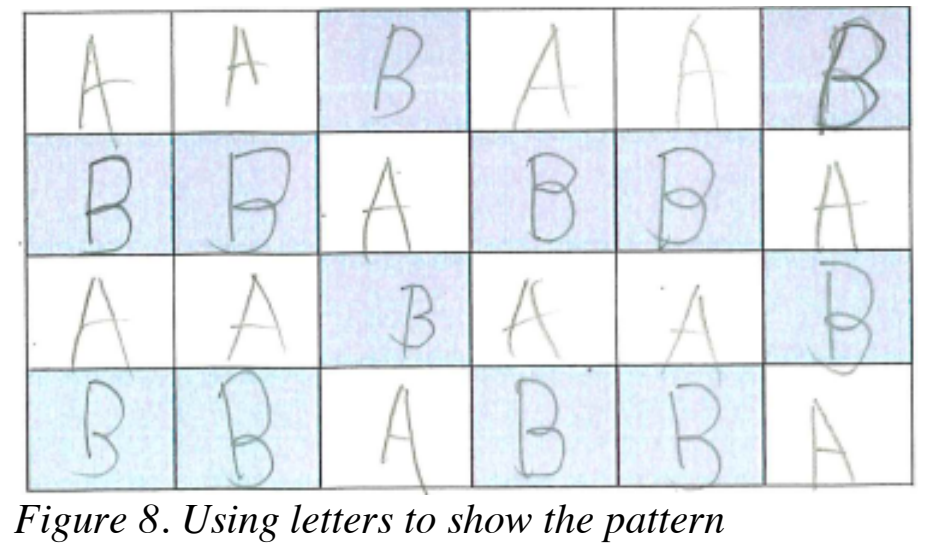

\begin{tabular}{|l|l|l|l|l|l|}
\hline$A$ & $B$ & $A$ & $B$ & $A$ & $B$ \\
\hline$A$ & $B$ & $A$ & $B$ & $A$ & $B$ \\
\hline$A$ & $B$ & $A$ & $B$ & $A$ & $B$ \\
\hline$A$ & $B$ & $A$ & $B$ & $A$ & $B$ \\
\hline
\end{tabular}

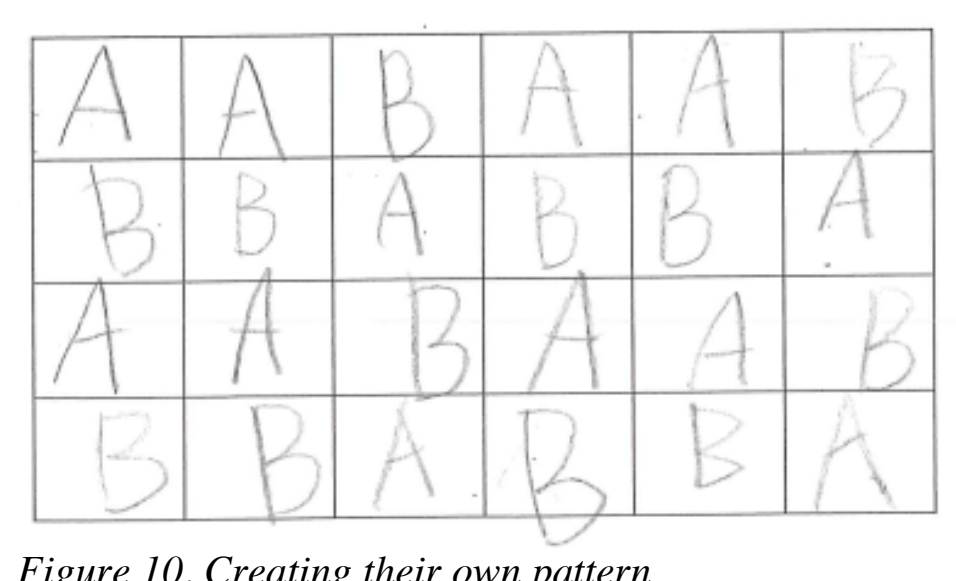

Figure 10. Creating their own pattern 


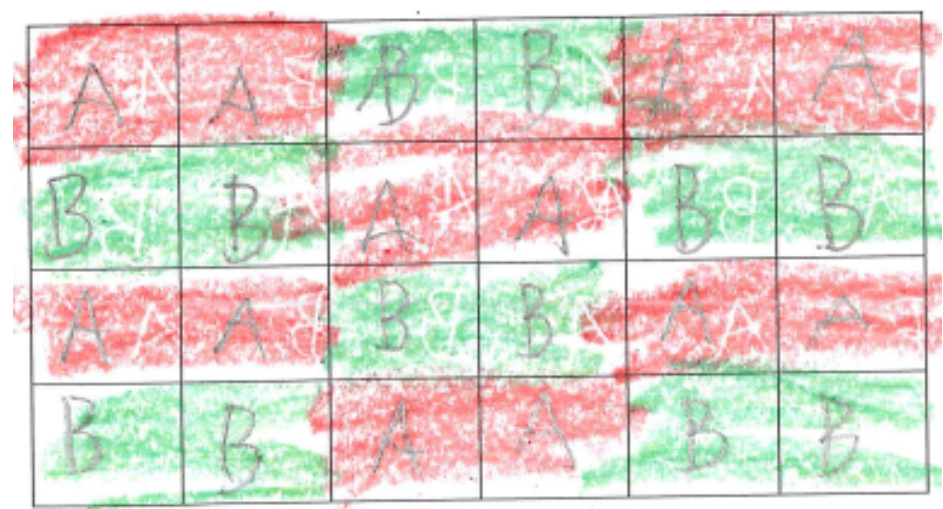

Figure 11. Creating their own pattern (AABB Pattern)

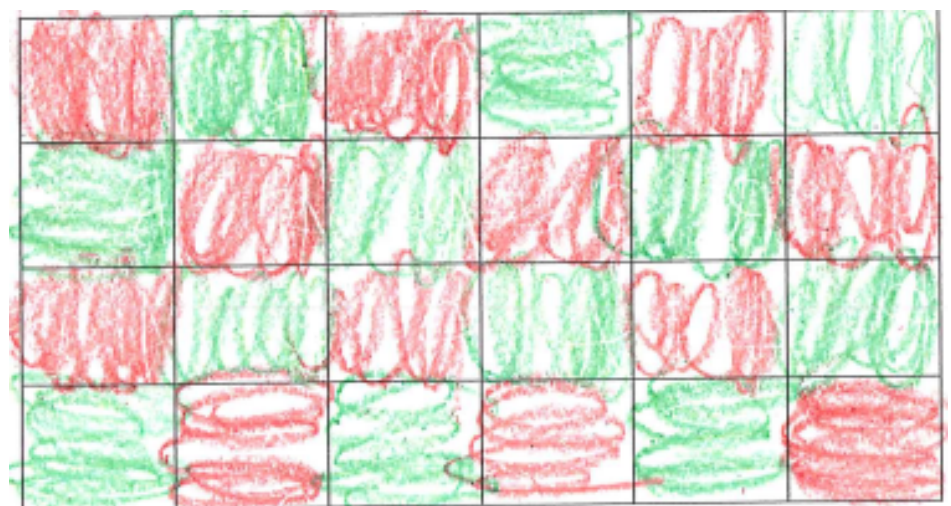

Figure 12. Creating their own pattern ( $A B A B$ Pattern)

In terms of the first grade level, students were engaged in lesson $4 \mathrm{~B}$ activity called Algorithms with Tangrams. Students worked with tangrams and sequencing after being introduced to the concept of algorithms. For this activity they follow series of instructions from the teacher to build images with the tangrams. Below, the transcription is an example of the instructions in the lesson 4B that lead students to build what they are being asked:

Step 1: Use the small triangle.

Step 2: Put the small triangle toward the top of your workspace.

Step 3: Rotate it so the long edge is toward the bottom.

Step 4: Use the medium triangle.

Step 5: Rotate it so the long edge is toward the bottom.

Step: 6 Put it below the small triangle so it touches in the middle.

Step 7: Use the large triangle.

Step 8: Rotate it so the long edge is toward the bottom.

Step 9: Put it below the medium triangle so it touches in the middle.

Step 10: Use the square.

Step 11: Put the side of the square below the large triangle so it touches it in the middle.

By following the sequence above, students were expected to form a tree as an outcome. When they completed the activity, they exhibited data representation, pattern recognition, and 
subtraction CT competencies. During the activity, they demonstrated the ability to do geometric translations by organizing and depicting data - the tangram shapes could be considered the data in this case. When they made relationships and represent the data - the tangram shapes - by building an image, they are actually experiencing the data representation CT competency. Another case of CT competency was that students exhibited pattern recognition and abstraction that happens when they observe the shapes and model a tree from them. For instance, from observing the dialog among the students, we noticed they perceive the final result as a tree and double arrow shapes (see Figure 13), what demonstrates they have recognized the respective patterns and abstraction. The following conversation occurred during the classroom activity between students to students and their teachers.

Danyel: [After he completed the sequencing activity] Oh, this is a tree!

Lara: [She concurred what Danyel stated it out] This is a tree.

Teacher: What is it?

Class: A treeee!

Lara: [After she completed the sequencing activity] Oh, an arrow!

Giovanna: [She concurred what Lara stated it out] It is an arrow.

Teacher: What is it?

Class: Arrowww!

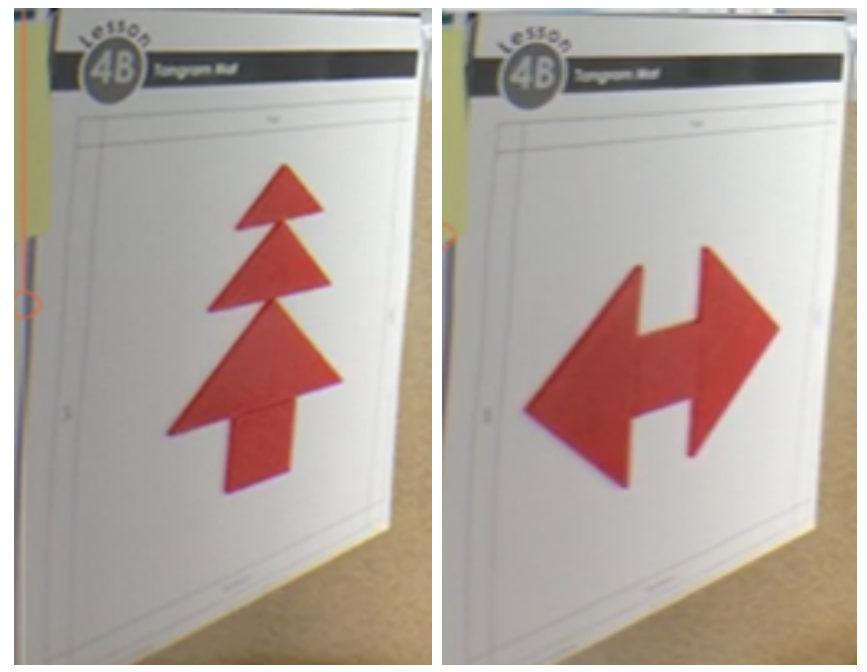

Figure 13. Algorithms with tangrams

Furthermore, students from second grade level were engaged in various engineering and computational thinking activities throughout the project. More specifically, during one lesson, the classroom teacher read a story called Henry's Map by David Elliott. The main character of the story is a pig, Henry, who liked to organize things. The story also includes other animals, such as, three sheep, a cow, a horse, and three chickens. When Henry realizes that his environment is in a mess, he starts to worry about the animals being able to find their own place. Therefore, he suggests a solution for each animal. He starts to draw a map that is designated for each animal's home (e.g., the woodshed and the coop). Throughout this activity, second graders were introduced to the idea of a mapping as well as following the correct steps stated in the story. They were given various cards with images on them from the story and were asked to 
place them in order. While doing the activity, students explicitly exhibited "sequencing" (as shown in the below Figure 14) and "debugging/troubleshooting" CT competencies.

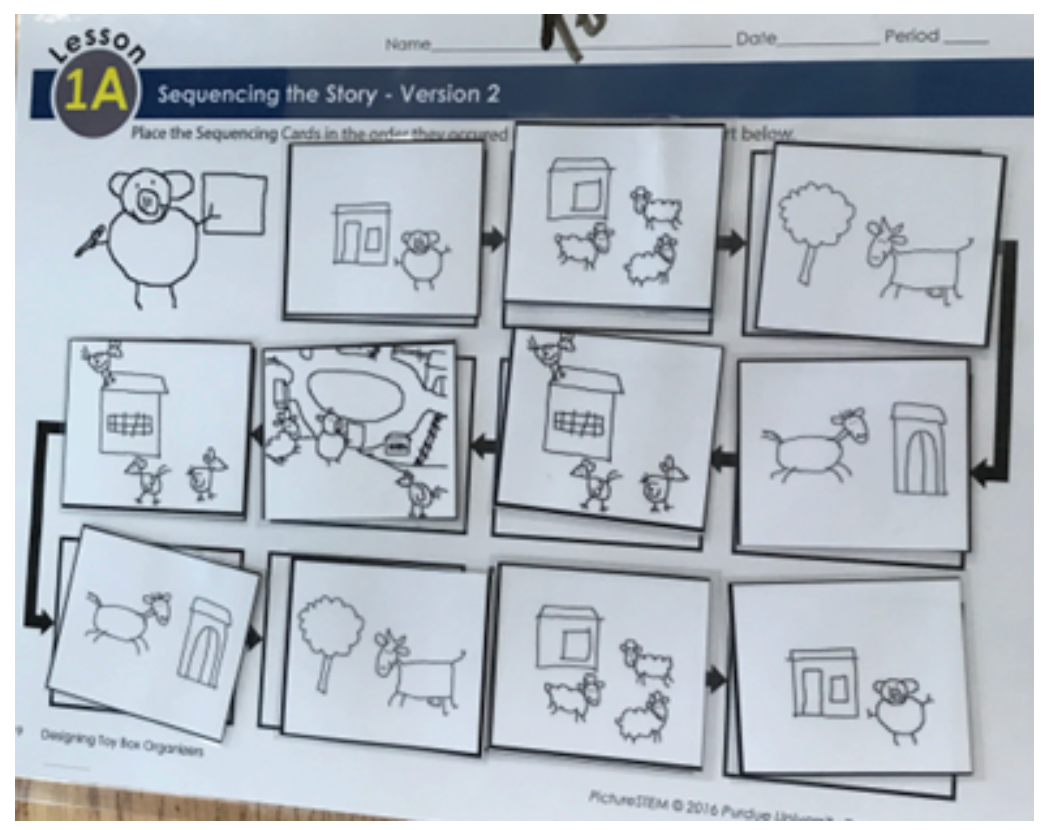

Figure 14. Sequencing the story-version 2

After second graders completed sequencing the cards, they were encouraged by the classroom teacher to compare their works with their peers. "Debugging/troubleshooting" CT competency happened in multiple examples during this activity. For instance, when Chloe completed the activity, Mira realized that her peer, Chloe, made a mistake in sequencing the story. Mira interfered with Chloe to point out the steps as indicated in the following conversation:

Mira: This is not how it goes.

Chloe: Yeah, it is [does].

Mira: I am saying to remember the story... It goes actually...

Chloe: [After understanding where she made the mistake] I remember.

Mira: It is in the wrong [step].

Chloe: I am remembering now. I remember now. [Chloe re-organized the cards in correct orders].

\section{Competencies as designed in Science Center Exhibit}

In this project, we also recognized that children can learn STEM+C in out-of-school settings. Therefore, to further support computational thinking amongst children in out-of-school settings, we developed an engineering $+\mathrm{CT}$ science center exhibit for K-2nd grade aged children. To inform the design of our exhibit, we first conducted some preliminary research on how families approach engineering+CT activities in a science center setting. To conduct this research, we developed a "Puppy Playground Challenge". The activity is an engineering design activity that also required children to use computational thinking competencies when designing their 
solutions. As seen in Figure 15, in this activity children are asked to build a playground for Eva's puppy using the big foam blocks (Figure 16). To characterize children's CT, we conducted indepth case studies of families as they engaged in this activity (Ehsan \& Cardella, 2017). The findings of this study provided evidence that children as young as 5 years-old are capable of engaging in various computational thinking competencies during an engineering design activity. These competencies include Abstraction, Algorithms and Procedures, Data collection, Debugging/troubleshooting, Pattern Recognition, Problem Decomposition, Parallelization and Simulation. These preliminary findings, our work with the curriculum, and modern engineering education research guided our decisions as we collaborated with our institution's Exhibit Design Center during a yearlong exhibit design process.

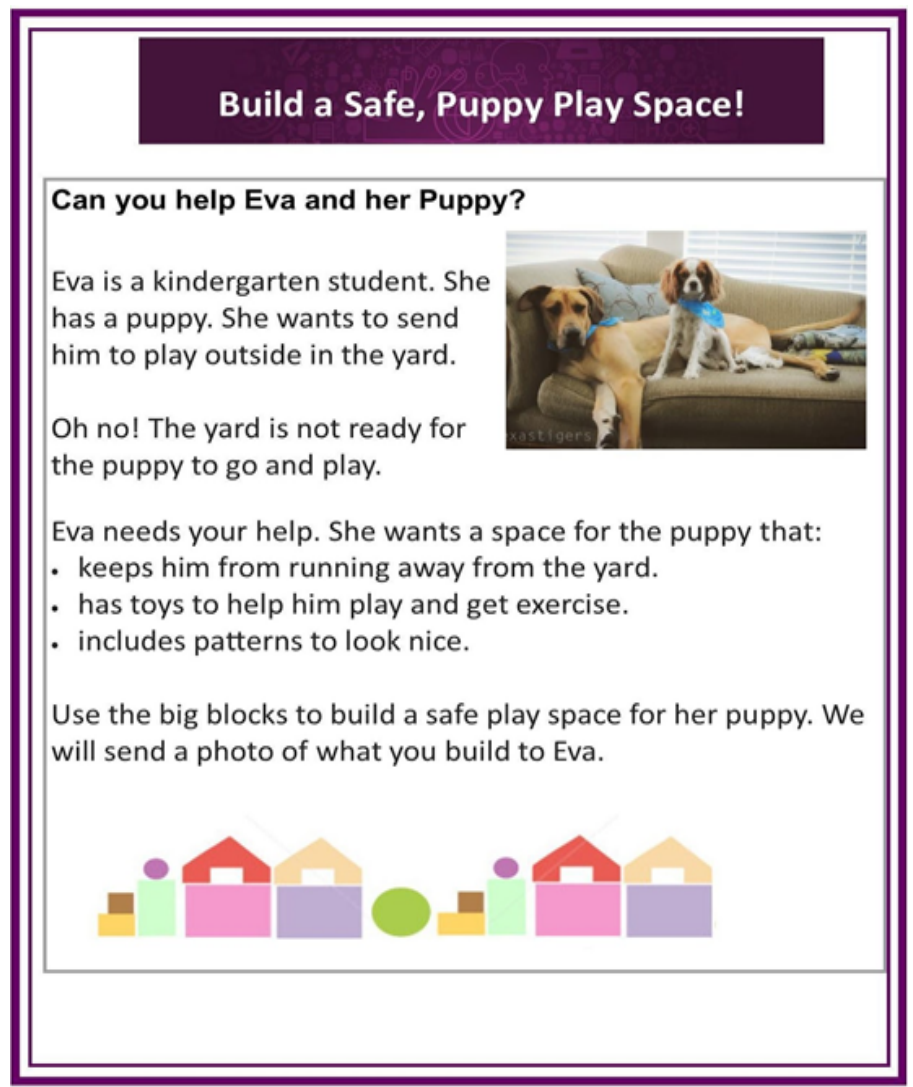

Figure 15. Build a puppy playground prompt 


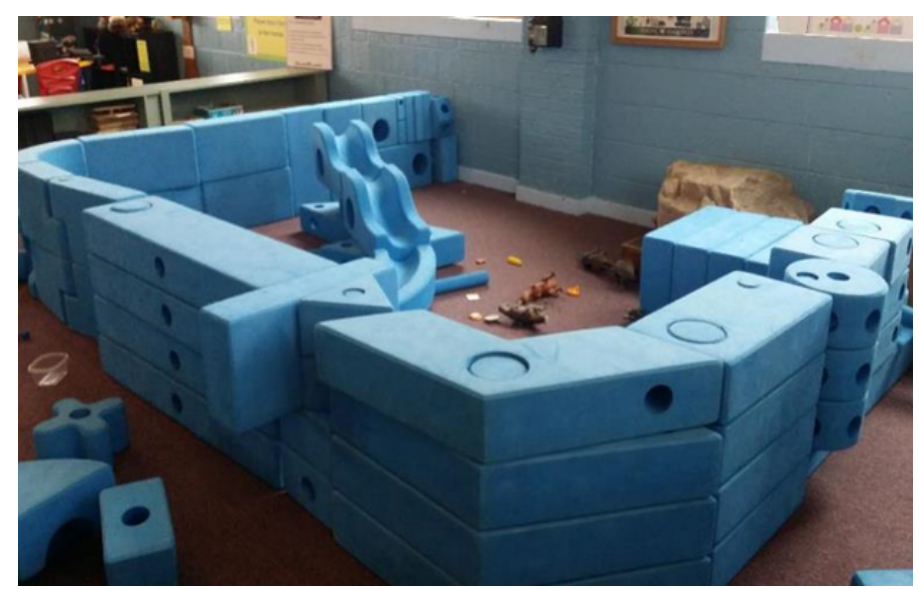

Figure 16. Foam blocks used to build a puppy playground at science center

At the beginning of the third year of project, we installed an engineering and computing exhibit called "Computing for the Critters" at our local science center. The goals of the exhibit are (1) to promote engineering interest amongst children who are racially and ethnically diverse and have differing abilities, and (2) to engage them in the process of computational thinking. The exhibit has three stations of unplugged (non-technology based) and plugged (technology-based) activities: (1) Play Structure (Figure 17), (2) Plan It!/Test It! (Figure 18) and (3) Computer-based coding game (Figure 19). In all of the activities, children have to help a robot find the quickest route to deliver medicine to three animals. At one station, children pretend to be the robot and deliver medicine themselves, whereas at the other stations, they provide instructions (i.e., code) to the robot to deliver medicine. The exhibit is designed to mainly promote CT as a problemsolving process, and emphasizes three CT competencies: Problem Decomposition, Algorithms and Procedures and Debugging/Troubleshooting. However, our research findings provide evidence of children engaging in more CT competencies (Ehsan, Dandridge, Yeter, \& Cardella, 2018). Below, we describe examples of how children and parents engaged in Problem Decomposition, Algorithms and Procedures and Debugging.

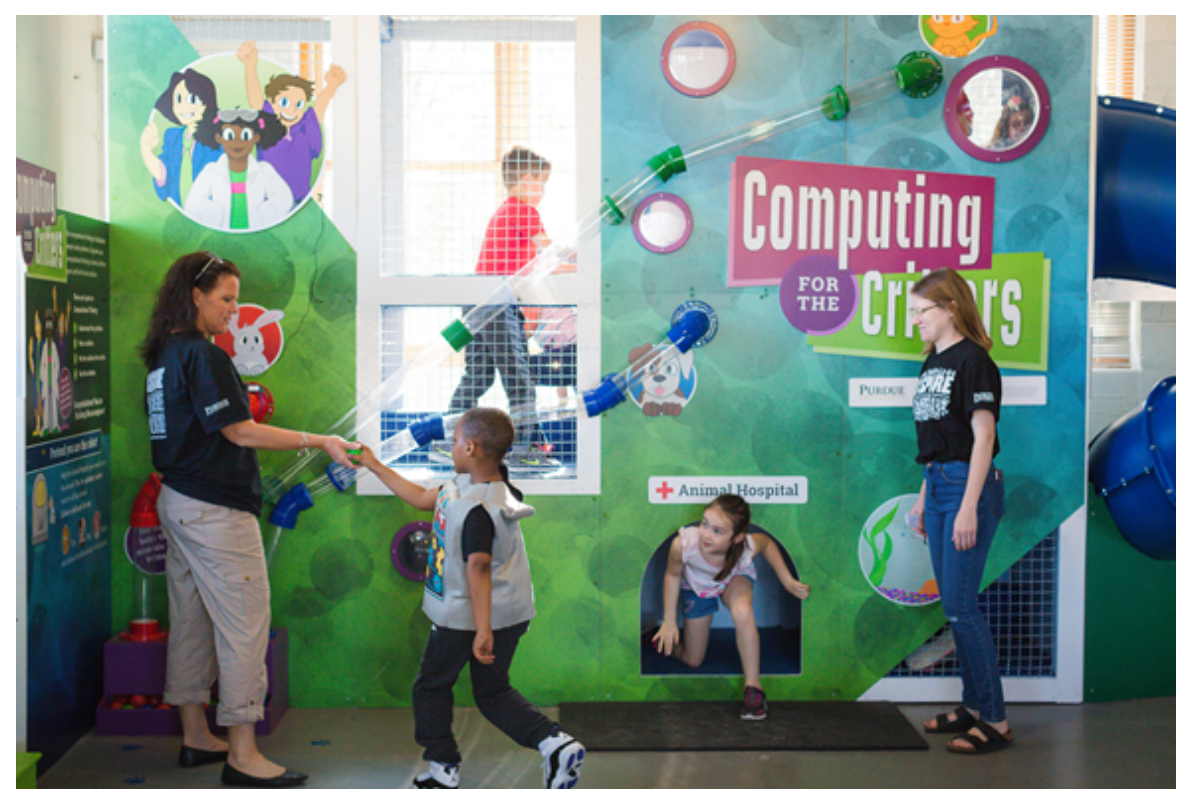


Figure 17. Science center computational thinking play structure

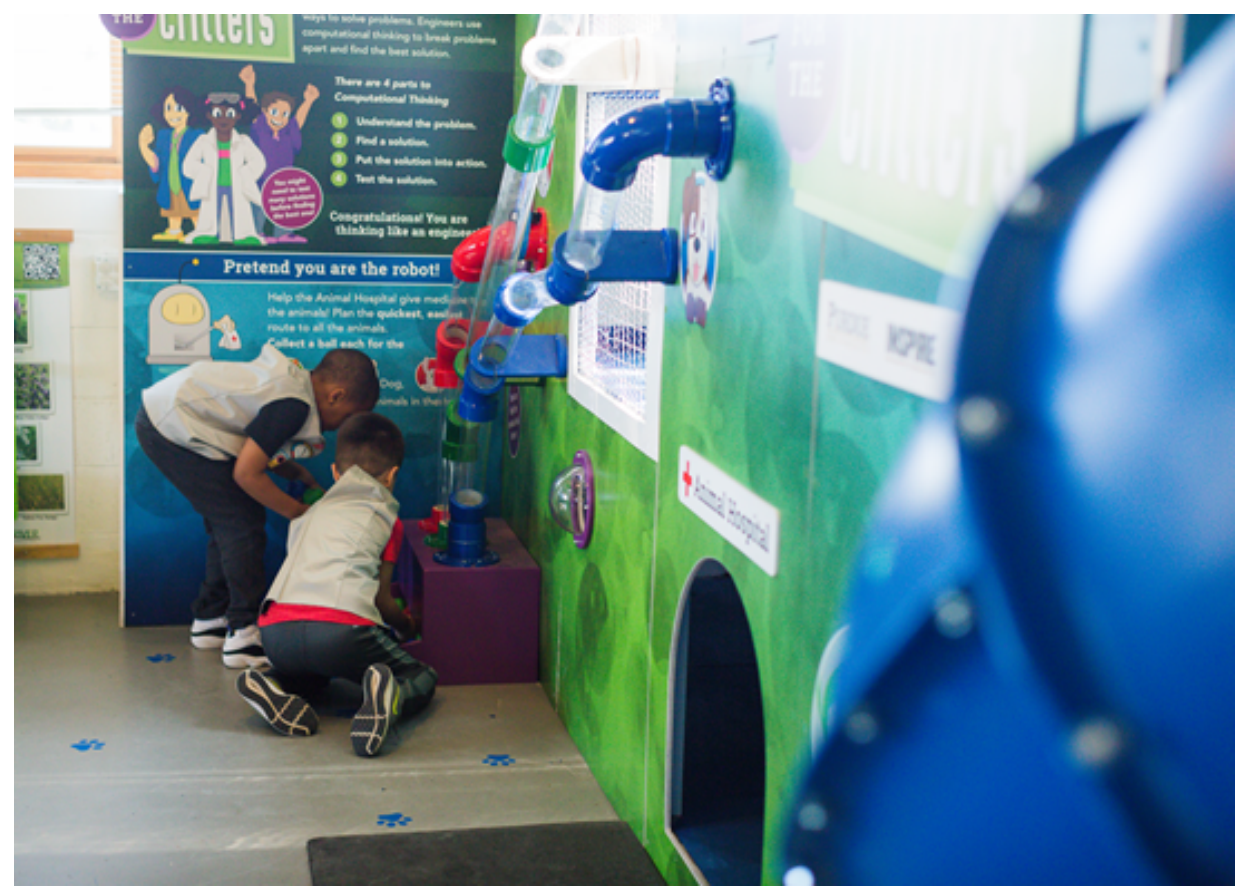

Figure 18. Science center computational thinking test it area

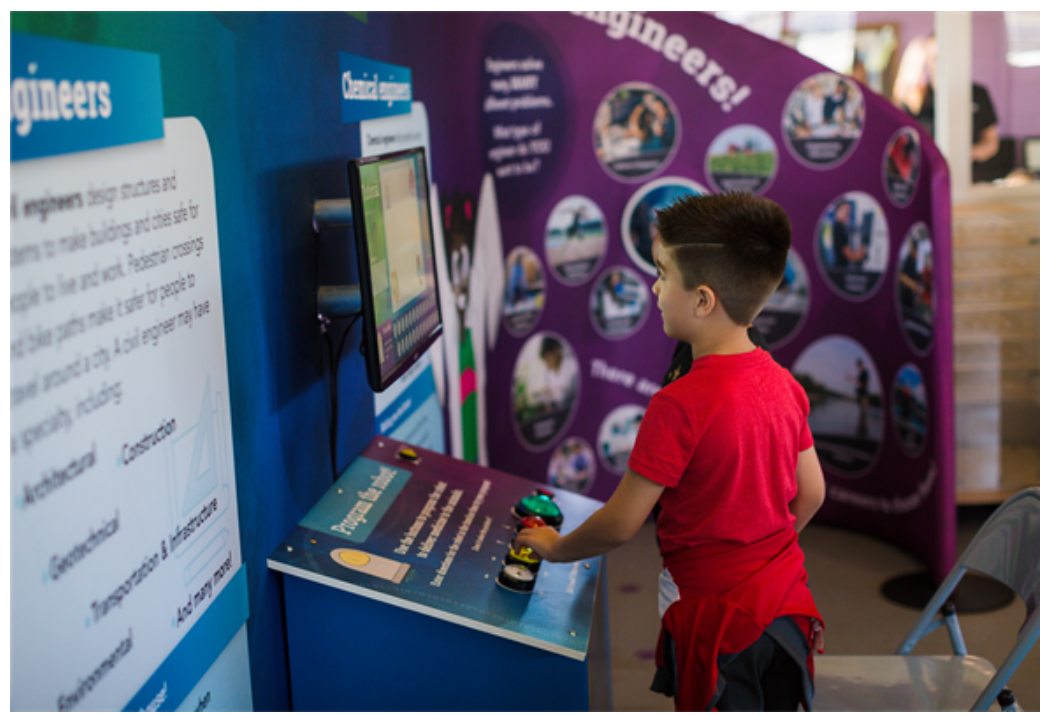

Figure 19. Science center computational thinking computer coding game

Problem Decomposition is breaking down the task into smaller and more manageable components to solve a problem. As families interacted with exhibit they have utilized this competency very often. For example, during the computer-based coding activity, the mom helped the child break down the problem:

Mom: Where should you go first? 
Child: To the cat?

Mom: How will you get to the cat?

The child enters the path from the robot's position to the cat.

Mom: Now from the cat to the dog?

The child enters the steps between the cat and the dog.

Mom: Now the dog to the rabbit?" and the child enters the necessary codes.

The mom assists the child with solving the problem by breaking it down to smaller paths to get to the animals. This way the child could enter smaller chunk of codes, and the test the code to see if it get to the first destination. Then, the child could code the robot to get the next animal.

Algorithm and Procedure is following, identifying and creating a set of instruction. During the family visit and interaction with the exhibit, we have observed frequent enactment of this competency. For example, while playing on the structure, the family plans for the fastest route to deliver medicine to the animals. The child creates a set of instructions by saying, "I can do red, blue and green, from the left" referencing taking the first left route from the entrance and going to the rabbit (which has the red color), then to the dog (which has the blue color) and finally to the cat (which has the green color).

Another example comes from a computer-based coding game where the parents read the instructions for their child and explain to the child the order the robot should deliver medicine to animals. The child enters necessary moves (codes) for the robot to get to the rabbit (i.e., Up, Up, Right, Right, Right, Down \& Down).

Debugging/Troubleshooting is when one identifies an error and/or addresses it. The exhibit activities provide opportunities for children to engage in debugging.

While playing in the structure, the child delivers all the balls (which are medicine) to the animals. Then, the mom and the child engage in debugging through the below conversation.

Mom: Was that the fastest way to do that?

Child: I do not know. No, it took a long time.

Mom: Let's see if we can plan better and try fastest ways?

Child: You can time me when I chose both ways.

Mom: that's a good idea, then we'll decide the fastest way.

Example 2. During the computer-based coding game, the child creates the code for the robot to get to the cat. She runs the code and notices an error. The mom then asks the child, "What do you think went wrong?" The child uses her fingers to see the path her code takes the robot, then resolves the error by deleting the last item of code and adding the right ones.

\section{Conclusions}

In this paper, we presented our project's curriculum development outputs in the form of revised integrated STEM plus CT lessons for K-2 classrooms and an engineering plus CT science center activity for young children and their parents. These were designed with the intention of engaging young students in the development of CT competencies. Our goal was to demonstrate what the process of translating CT competencies into activities for young children looks like as well as 
what the resulting engagement looks like from the students and their parents. While many of the examples we shared likely do not mirror what these competencies would look like for older students engaged in computer programming courses, we believe it is important to think about what they do look like among younger children. This sort of early exposure can help students better identify themselves as pursuing futures along STEM and CT pathways.

\section{Acknowledgements}

We would like to thank all the students, teachers, and parents who participated in this project. They were enthusiastic and engaged throughout! This material is based upon work supported by the National Science Foundation under Grant No. 1543175. Any opinions, findings, and conclusions or recommendations expressed in this material are those of the author(s) and do not necessarily reflect the views of the National Science Foundation. 


\section{References}

Barr, V., \& Stephenson, C. (2011). Bringing computational thinking to K-12: what is Involved and what is the role of the computer science education community? ACM Inroads, 2(1), 48-54.

Brennan, K., \& Resnick, M. (2012). New frameworks for studying and assessing the development of computational thinking. In Proceedings of the 2012 annual meeting of the American Educational Research Association, Vancouver, Canada.

Computer Science Teacher Association (CSTA), \& International Society for Technology in Education (ISTE). (2011). Computational thinking teacher resources (Second ed.).

Czerkawski, B. C., \& Lyman, E. W. (2015). Exploring issues about computational thinking in higher education. TechTrends, 59(2), 57-65. doi:10.1007/s11528-015-0840-3

Dandridge, T. M., Ehsan, H., Gajdzik, E., Lowe, T., Ohland, C., Yeter, I. H., Brophy, S., \& Cardella, M. E. (2019, February). Integrated STEM+ C learning for K-2 aged children: CT competencies as a precursor to K-2 computer science education. In Proceedings of the 50th ACM Technical Symposium on Computer Science Education (pp. 1280-1280). ACM.

Ehsan, H., \& Cardella, M. E. (2017). Capturing the computational thinking of families with young children in out-of-school environments. In Proceedings of the American Society for Engineering Education (ASEE) Conference \& Exposition. Columbus, $\mathrm{OH}$.

Ehsan, H., Dandridge, T. M., Yeter, I. H., \& Cardella, M. E. (2018, June). K-2 students' computational thinking engagement in formal and informal learning settings: A case study (fundamental). In Proceedings of the American Society for Engineering Education (ASEE) Conference \& Exposition. Salt Lake City, Utah.

Grover, S., \& Pea, R. (2013). Computational thinking in K-12: A review of the state of the field. Educational Researcher 42(1), 38-43. doi:10.3102/0013189X12463051

Hynes, M. M., Moore, T. J., Cardella, M. E., Tank, K. M., Purzer, S., Menekse, M., \& Brophy, S. P. (2016). Inspiring computational thinking in young children's engineering design activities (fundamental). In Proceedings of the American Society for Engineering Education (ASEE) Conference \& Exposition. New Orleans, Louisiana.

Lowe, T., Brophy, S., \& Cardella, M. (2019, February). Exploring the definition of computational thinking in research and the classroom. In Proceedings of the 50th ACM Technical Symposium on Computer Science Education (pp. 1277-1277). ACM.

Lye, S. Y., \& Koh, J. H. L. (2014). Review on teaching and learning of computational thinking through programming: What is next for K-12? Computers in Human Behavior, 41, 5161. doi:10.1016/j.chb.2014.09.012

Moore, T. J., Stohlmann, M. S., Wang, H. H., Tank, K. M., Glancy, A. W., \& Roehrig, G. H. (2014). Implementation and integration of engineering in K-12 STEM education. In S. Purzer, J. Strobel, \& M. E. Cardella (Eds.) Engineering in pre-college settings: Synthesizing research, policy, and practices. Purdue University Press.

National Research Council. (2011). Committee for the Workshops on Computational Thinking: Report of a workshop of pedagogical aspects of computational thinking. Washington, D.C.

Roehrig, G. H., Moore, T. J., Wang, H.-H., \& Park, M. S. (2012). Is adding the E enough? Investigating the impact of K-12 engineering standards on the implementation of STEM integration. School Science and Mathematics, 112(1), 31-44. 
Wing, J. M. (2006). Computational thinking. Communications of the ACM, 49(3), 33-35. 